\title{
Operationalizing water-energy-food nexus research for sustainable development in social-ecological systems: an interdisciplinary learning case in Central Asia
}

${\frac{\text { Ahmad Hamidov }}{\text { Seerat }^{7}}}^{1,2}, \underline{\text { Katrin Daedlow }}^{3}, \underline{\text { Heidi Webber }}^{1}, \underline{\text { Hussam Hussein }}^{4,5}, \underline{\text { Ilhom Abdurahmanov }}^{2}, \underline{\text { Aleksandr Dolidudko }}^{6}, \underline{\text { Ali Yawar }}^{9}$ Seerat $^{7}$, Umida Solieva ${ }^{8}$, Tesfaye Woldeyohanes ${ }^{9}$ and Katharina Helming $^{1}, 10$

\begin{abstract}
In social-ecological systems, natural resource management can be characterized by trade-offs across sectors and sustainability targets. The water-energy-food (WEF) nexus concept makes explicit various trade-offs in order to maximize synergies of interventions. However, there are few successful examples of its operationalization in research settings. Here, we explore in a learning setting if sustainability impact assessment (SIA) protocols can be a useful process to be used to adopt a systemic, interdisciplinary perspective to operationalize WEF nexus in research for sustainable development. The process and method adopted of SIA protocol, evaluated for five exemplary WEF nexus cases in Central Asia during a week-long international workshop, adequately addressed the complexity of WEF interrelationships and associated sustainability issues, and facilitated a comparative case study analysis across scales. Results within this process highlight that water governance was critical for large-scale transboundary WEF nexus management, while land and soil management were decisive for minimizing trade-offs at local levels. Issues of interdisciplinarity, complexity, uncertainty, and reflection on impacts were adequately addressed, but challenges remain in the consideration of ethics and the design of transparent, multi-actor cooperation. Most importantly, this exercise showed that employment of the process of SIA protocol supported disciplinary experts to work across disciplines and take a systemic approach for analyzing WEF nexus.
\end{abstract}

Key Words: Afghanistan; Central Asia; impact assessment; interdisciplinarity; socially responsible research; systemic approach

\section{INTRODUCTION}

The perfect storm of competition and trade-offs between water, energy, and food (WEF) as they interact with the environment and climate is illustrated by the catastrophic drying of the Aral Sea basin (Jalilov et al. 2018), once the world's fourth largest inland water body (Löw et al. 2018). A lack of systemic approaches to natural resource management has resulted in serious environmental degradation and social consequences in the region (Djumaboev et al. 2020). With six Central Asian countries making up the Aral Sea basin (Afghanistan, Kazakhstan, Kyrgyzstan, Tajikistan, Turkmenistan, and Uzbekistan), a complex mix of geopolitical, economic, environmental, historical, and social-cultural factors determine water use in the region. The relative importance of irrigated agriculture, hydropower generation, water diversion for municipal use, and subsequent environmental consequences varies by country. However, the conflicting demands on water transcend transboundary water issues and include trade-offs at local levels as well (Jalilov et al. 2016). The Aral Sea case makes clear the need to consider linked dynamic systems between ecology and society, increasing our understanding of their mutual influences and feedbacks.

Examples such as the Aral Sea case call for adopting WEF nexus concepts (D'Odorico et al. 2019). In simultaneously considering water, energy, and food, the WEF nexus concept aims to support the transition toward sustainable solutions for social-ecological systems by identifying potential synergies and minimizing tradeoffs between the three elements (Hoff 2011, Albrecht et al. 2018). Simultaneously, the WEF nexus framework allows us to contextualize and consider both the ecological and societal dimensions, as they interact. Nevertheless, operationalization of the WEF nexus concept remains challenging (Hamidov and Helming 2020). This is explained in part by the lack of methodologies to address and quantify systemic interlinkages between elements of the nexus (Endo et al. 2020) together with limited interdisciplinary communication and coordination between sectors (Weitz et al. 2017), minimal investments in resilience-oriented nexus tools (Keulertz and Woertz 2015), and lack of broader involvement of stakeholders for bringing the nexus theory into practice (Fabiani et al. 2020). Such methodological challenges are typical for sustainability transitions research (Köhler et al. 2019).

Here, sustainability impact assessment (SIA) is proposed as a process and a learning tool to improve systemic thinking for the operationalization of the WEF nexus concept, addressing at least the first two of the above challenges. SIA is increasingly used to provide scientific support to policy and management decision making (Helming et al. 2011). Actors from various disciplines

\footnotetext{
${ }^{1}$ Leibniz Centre for Agricultural Landscape Research (ZALF), Germany, ${ }^{2}$ Tashkent Institute of Irrigation and Agricultural Mechanization Engineers (TIIAME), Uzbekistan, ${ }^{3}$ Agriculture and Food Policy Group, Humboldt-Universität zu Berlin, Germany, ${ }^{4}$ Department of Politics and International Relations (DPIR), University of Oxford, UK, ${ }^{5}$ International Agricultural Policy and Environmental Governance, University of Kassel, Germany, ${ }^{6}$ Scientific Research Institute of Irrigation and Water Problems, Uzbekistan, ${ }^{7}$ Faculty of Agriculture, Bamyan University, Afghanistan, ${ }^{8}$ Department of Environmental Sciences and Policy, Central European University, Austria, ${ }^{9}$ Center for International Forestry Research (CIFOR)World Agroforestry (ICRAF), Kenya, ${ }^{10}$ University for Sustainable Development (HNEE), Germany
} 
jointly articulate the problem to be addressed, formulate objectives, and propose intervention scenarios. From this initial shared conception, indicator frameworks are developed to assess the intended and unintended impacts and identify associated risks. The evaluation of assessment results transparently incorporates normative values (Binder et al. 2010) to construct a shared understanding of the problem and possible solutions (Bertelsen 2000). In applying SIA protocols to operationalize WEF nexus concepts, scenarios are analyzed and trade-offs associated with possible solutions are identified for competing sectors, the environment, communities, and/or interest groups. Trade-off analysis itself can make use of a combination of disciplinary and integrated modeling tools (Kling et al. 2017) and a range of qualitative, participatory approaches (König et al. 2012). As a largely ex-ante analysis, SIAs are able to address many of the key characteristics of socially responsible research processes (Daedlow et al. 2016) and sustainability transitions research (Köhler et al. 2019). As such, SIA integrates elements of more disciplinary assessments such as environmental impact assessment (Morgan 2012) or social impact assessment (Esteves et al. 2012) in achieving an interdisciplinary perspective. However, to date, SIA has not been applied to the analysis of WEF nexus problems.

The objectives of this article were to examine (1) the extent to which SIA is a suitable learning tool to adopt a systemic, interdisciplinary approach to WEF nexus problems, (2) the degree to which SIA can support sustainable development research in the context of WEF nexus challenges, and (3) whether the implementation of a common SIA protocol supports synthesis across WEF nexus cases. We used five exemplary case studies from Central Asia to address this objective.

\section{METHODS}

The research consisted of two consecutive steps. The first step was implemented as a training exercise. Five case studies in Central Asia around irrigated agriculture were developed, and an SIA protocol was applied in analyzing each case study. This was performed during a week-long international workshop with 36 experts from Central Asia with backgrounds spanning economics, social sciences, agricultural sciences, and engineering, trained by experts in sustainability research. The Central Asian experts brought expertise on the WEF challenges and possible future development pathways but mostly lacked systems research experience on how to conceptualize the WEF nexus challenge for an SIA. Irrigated agriculture was selected as an overarching topic given it is an illustrative, cross-scale example of WEF nexus problems (Djumaboev et al. 2019) and its central relevance for food production and economic well-being in Central Asia (Hamidov et al. 2016). The geographic extent of the case studies ranged from international transboundary watersheds to very local scales, with a diversity of actors and sectorial focal issues. The experts in sustainability research had backgrounds in SIA, systems modeling, and social-ecological system research. The second step was implemented as a reflection exercise. It consisted of the analysis for each case study of how the SIA protocol application contributed to improving the capability of the experts to address systemic nexus issues and design sustainability research. The appropriateness of the SIA protocol as a research tool for WEF nexus problems was qualitatively evaluated by applying a self-reflection tool for socially responsible research (Daedlow et al. 2016).

\section{Implementation of the sustainability impact assessment protocol} for case studies in Central Asia

Case study elaboration

The study was conducted during a one-week international summer school that took place in May 2019 in Tashkent, Uzbekistan. The aim was to share experiences and insights on cross-scale sustainability problems related to WEF nexus issues of irrigated agriculture and to improve participants' capacity in the multidimensional, multi-perspective conceptualization of sustainability problems. A key intended outcome was for participants to operationalize the WEF nexus through SIA protocol for five case studies from Central Asia.

The participants were selected in a competitive process using the following criteria: (1) motivation for interdisciplinary agricultural research, (2) conduct research in the area, (3) background in fields related to irrigated agriculture, (4) balanced representation of a range of disciplines by the participants, (5) geographical balance of the participants, (6) gender balance, and (7) proficiency in English. The selected participants came from 10 countries and had complementary disciplinary backgrounds (agronomy, economics, ecology, water engineering, hydrology, energy, ethnography, forestry, information technology, and biology). The participants were scientists at $\mathrm{PhD}$ and post-doctoral level from this region, representing the region's research institutes most actively working on WEF issues. The lecturers were trained in sustainability assessment, systems analysis, and WEF nexus research.

The 36 regional experts formed five groups that each developed a case study topic to operationalize the WEF nexus concept applying an SIA protocol. Although the case studies represent very close to real world scenarios in the region, given the limited time available (one week), they served as mock exercises in which stakeholder interaction was replaced by role play and data analysis was replaced by expert assumptions. Within their groups, experts were assigned roles of various individual stakeholders and negotiated based on that role. Stakeholder roles included representatives from ministries (e.g., of agriculture, water, and environment), universities, resource users, donor organizations, and civil society. At the end of the workshop, all study groups highlighted and further confirmed that the WEF challenges discussed in their group were good reflections of real world problems. The exercise spanned the entire impact assessment process with the explicit aim to explore whether SIA could operationalize WEF nexus and contribute to sustainability outcomes. On the final day of the workshop, participants reflected on the process of the entire exercise by presenting and discussing the results of their group work as well as elaborating on what they learned related to WEF nexus implementation and suitability of the SIA protocol, challenges related to interdisciplinary thinking, and the rigorous and data-heavy analysis required to analyze trade-offs.

\section{Sustainability impact assessment protocol}

The SIA protocol consists of an established sequence of six consecutive steps as defined in the Impact Assessment guidelines of the European Commission (CEC 2009) and often utilized for social-ecological systems in research settings (Helming et al. 2013): (1) identification of the problem (including definition of sustainability targets), (2) formulation of the policy/management objectives, (3) development of alternative policy/management 
Fig. 1. Five steps of the sustainability impact assessment (SIA) protocol (Helming et al. 2013) and their link to design-artefact dimensions (Bertelsen 2000).

\begin{tabular}{|c|c|c|}
\hline 1. Identify the problem & & \multirow{5}{*}{$\begin{array}{l}\text { Cooperation } \\
\text {... is the representational } \\
\text { relation between subjects } \\
\text { involved in the design }\end{array}$} \\
\hline 2. Define the objective & $\begin{array}{l}\text { the designing subjects and the } \\
\text { historically developing activity }\end{array}$ & \\
\hline 3. Develop options / scenarios & \multirow{3}{*}{$\begin{array}{l}\text { Construction } \\
\text {... is the productive relation } \\
\text { between the designing subject } \\
\text { and the object of design }\end{array}$} & \\
\hline 4. Analyze the impacts & & \\
\hline 5. Compare the options / scenarios & & \\
\hline
\end{tabular}

options scenarios and specification of the key indicators to quantify in the trade-off analysis, (4) analysis of impacts related to the defined sustainability targets, (5) comparison of the impacts, and (6) implementation of the selected best option. As the SIA protocol was used here in an educational and research setting, we disregarded the implementation phase (step 6, Fig. 1). For each developed scenario (step 3) in each case study, the participants used expert opinion to assess the likelihood of the impacts according to the following scale: $0=$ no impact; -1 and $+1=$ moderate negative and positive impact, respectively; -2 and $+2=$ high negative and positive impact, respectively; and -3 and $+3=$ extremely high negative and positive impact, respectively (König et al. 2013). Results of the assessment were summarized in chart diagrams. To facilitate comparison between the cases and to provide a clear connection to sustainability issues, the assessed impact variables were mapped by group participants to relevant Sustainable Development Goals (SDGs): SDG 2 (food security and sustainable agriculture), SDG 6 (sustainable management of water) and SDG 7 (modern energy), as well as SDG 3 (healthy lives and well-being for all), SDG 8 (sustainable economic growth), SDG 11 (sustainable cities and communities), and SDG 15 (sustainable use of terrestrial ecosystems).

The SIA protocol is generic to research for sustainable development (Pintér et al. 2012) and policy support (Reidsma et al. 2018). It is also a mandatory element of policy making at the European Commission (Bäcklund 2009). Applied with participatory methods, it has proven to be a useful tool for codesigning research (Mackenzie and Davies 2019). Therefore, we believe that the protocol can support the design of WEF nexus research from a sustainability perspective.

Scientists or stakeholders working with researchers using SIA protocols influenced the design of the six steps, which in turn influenced the assessment results through their specific expertise, norms, and values. To address the degree to which the implementation of the SIA protocols and steps followed by the participants had trained their systems perceptions, insights from design science (Jones and Gregor 2007) were considered, specifically the design artefact concept (Bertelsen 2000). Originally focused on the study of IT-based system solutions, the design artefact can be used in the context of agriculture and WEF nexus as a method to facilitate user-centered features to key actor groups through their engagement and the roles they play in decision support (Miah et al. 2014). The three design dimensions relevant to this study consist of conception, construction, and cooperation (Bertelsen 2000; Fig. 1). The conception of the impact assessment by participating actors is primarily undertaken in the first two assessment steps where actors identify research problems and objectives, defining the system's boundaries. The construction of the impact assessment occurs largely in steps three to five, in the creation of scenarios, choice of indicators, and the comparative valuation of the impact assessment results. Finally, cooperation is evidenced throughout all impact assessment steps, influencing conception and construction in a largely iterative manner.

The five cases were qualitatively compared on the basis of both SIA impact assessment results as well as across the three design artefact dimensions. These two approaches allowed an evaluation of the interdisciplinary, systems approach of the cases from a thematic and a conceptual perspective. The comparison was important to assess the suitability of the protocol, and it allowed us to synthesize similarities and differences across the cases that share a common WEF nexus pattern.

\section{Suitability of the sustainability impact assessment protocol to operationalize WEF nexus related sustainability research}

To further assess whether and to what extent use of the SIA protocol could improve experts' ability to address sustainability challenges related to the WEF nexus problems, the integrated assessment framework for socially responsible research processes was considered (Daedlow et al. 2016). The framework defines eight criteria (Table 1) that can be used for self-reflection on a research process. The framework was applied in a follow-up workshop with a subgroup of the participants of the first workshop representing each case study, approximately six months later. To promote impartiality and avoid anticipatory adaptation to the criteria during the case study design, the participants did not know at the first workshop that there would be a follow-up ex-post evaluation of their impact assessment protocols.

In implementing the framework, group representatives were asked to describe and assess in a self-reflection approach to which extent the criteria played a role in their WEF nexus impact assessment group work. They assessed each of the eight criteria by assigning the following numbers (signs): $0=$ the criterion were of no importance, i.e., there was no discussion about the issues addressed by this criterion during the impact assessment design process; 1 = the criterion were of minimal importance, i.e., the issues addressed by this criterion were implicitly discussed, but not particularly considered in the impact assessment design process; 2 the criterion were of moderate importance, i.e., the issues addressed by this criterion were directly discussed and 
Table 1. Criteria to assess socially responsible research processes for sustainability transformation.

\begin{tabular}{ll}
\hline \hline Criteria & Characterization \\
\hline $\begin{array}{l}\text { Approach to complexity and } \\
\text { uncertainty }\end{array}$ & $\begin{array}{l}\text { Evaluation of emerging risks and societal consequences emerging from dynamic and complex interactions that } \\
\text { increase uncertainty in any form of inference } \\
\text { Ethics }\end{array}$ \\
$\begin{array}{l}\text { Ethical, moral and value related questions affecting the society induced by research results, methodological } \\
\text { designs and the determination of the value of science itself } \\
\text { Consideration of all relevant elements, and interrelations in complex and multifaceted processes of modern } \\
\text { societal development that are addressed by the research questions thereby integrating different dimensions (e.g., } \\
\text { themes, time, space and knowledge systems) } \\
\text { Integration of mindsets and methods from different scientific disciplines to develop new methodological } \\
\text { approaches and research results }\end{array}$ \\
Interdisciplinarity & $\begin{array}{l}\text { Assessment of the benefits and risks of research outcomes and innovations for the society and for sustainable } \\
\text { development (e.g. intended/unintended, positive/negative, ex-ante/post) } \\
\text { Integration of knowledge via engaging non-scientific actors in specific scientific discourses and research } \\
\text { questions, e.g. through participatory methods }\end{array}$ \\
Clear and user-oriented communication about funding, legitimation, research design, methods and their limits \\
Transdisciplinarity & $\begin{array}{l}\text { and impacts on research results in all stages of the research process } \\
\text { increase usability and integration in science and society }\end{array}$ \\
Transparency &
\end{tabular}

Source: Daedlow et al. 2016:4

considered to some extent in the impact assessment design process; $3=$ the criterion were of significant importance, i.e., the issues addressed by this criterion were thoroughly discussed and had an important influence on the impact assessment design process. At the end of the process, the case study representatives and the lecturers discussed the relative merits and shortcomings of the self-reflection exercise.

\section{WEF NEXUS CASES RELATED TO IRRIGATED AGRICULTURE IN CENTRAL ASIA}

All of the five empirical cases addressed the challenge of water resource use for food and/or energy production in Central Asia, although they differed in geographic scope (Fig. 2). The origins of tensions between water use for food and energy stem to the Soviet era (1920-1991) when a transboundary water management system existed for the two main Central Asian rivers of the Aral Sea basin: Amudarya and Syrdarya. The system included water storage in the upstream countries (Kyrgyzstan and Tajikistan), in winter and spring for release in summer, to meet the demand for irrigation of agricultural fields in the downstream countries (Kazakhstan, Turkmenistan, Uzbekistan; Kasymov and Hamidov 2017). Whereas the upstream countries are rich in water, and as a result in hydropower potential, they lack significant reserves of fossil fuels. On the other hand, downstream countries have limited water resources but abundant fossil fuel reserves. During the Soviet era, downstream countries provided the upstream countries with energy, particularly in the winter when energy requirements are highest for heating (Qi et al. 2020) as part of the centrally managed economic system.

However, this system of water allocation and use was associated with severe environmental impacts including large-scale soil degradation through salinization processes and the devastation of the Aral Sea as flow volumes were drastically reduced (Yu et al. 2019). The construction of large-scale irrigation schemes to cultivate cotton to secure the Soviet Union's "cotton independence" was largely responsible for the widespread environmental degradation in the sea zone (Soroush 2018). With the collapse of the Soviet Union, the transboundary governance
Fig. 2. Location of the five case study areas in Central Asia (own graph, generated using ArcGIS).

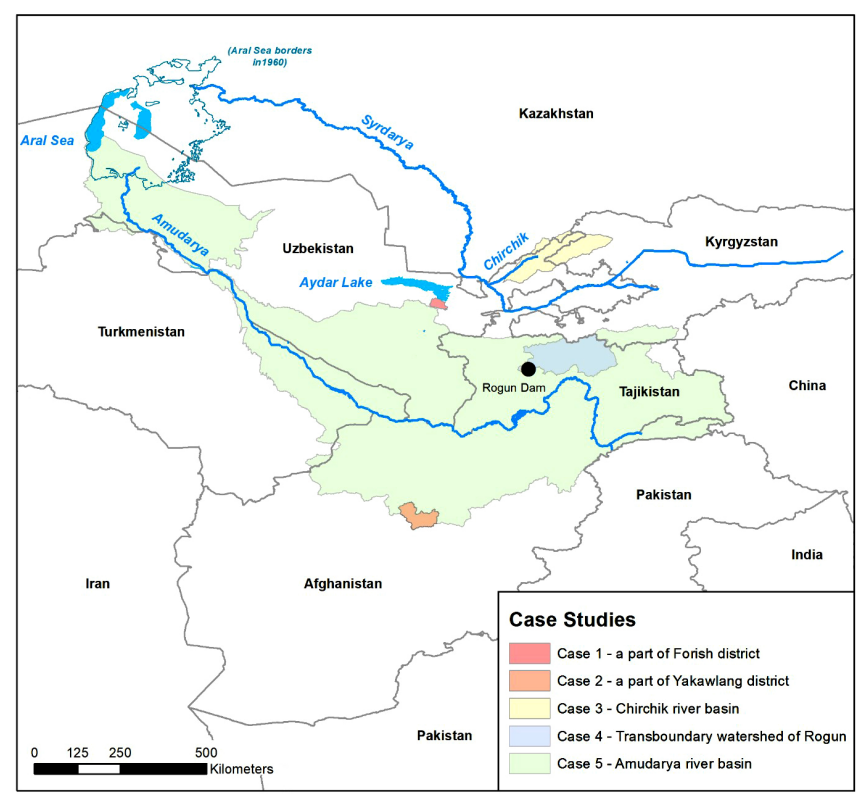

system of fossil fuel provisioning and water allocation was abandoned. Upstream countries constructed large-scale dams in their territories to keep water during summer season for hydropower generation, resulting in reduced availability for crop irrigation in downstream countries (Howard and Howard 2016). In addition, the release of upstream water during winter periods for hydropower generation caused considerable flooding and related environmental damage in downstream countries (Micklin 2016). As a result, farmers in the downstream regions faced significant water shortages and land degradation, and are unable to adequately irrigate their crops, resulting in decreased agricultural production across the basin. Meanwhile, downstream 
Table 2. Application of the sustainability impact assessment (SIA) protocol to the water-energy-food (WEF) nexus case studies.

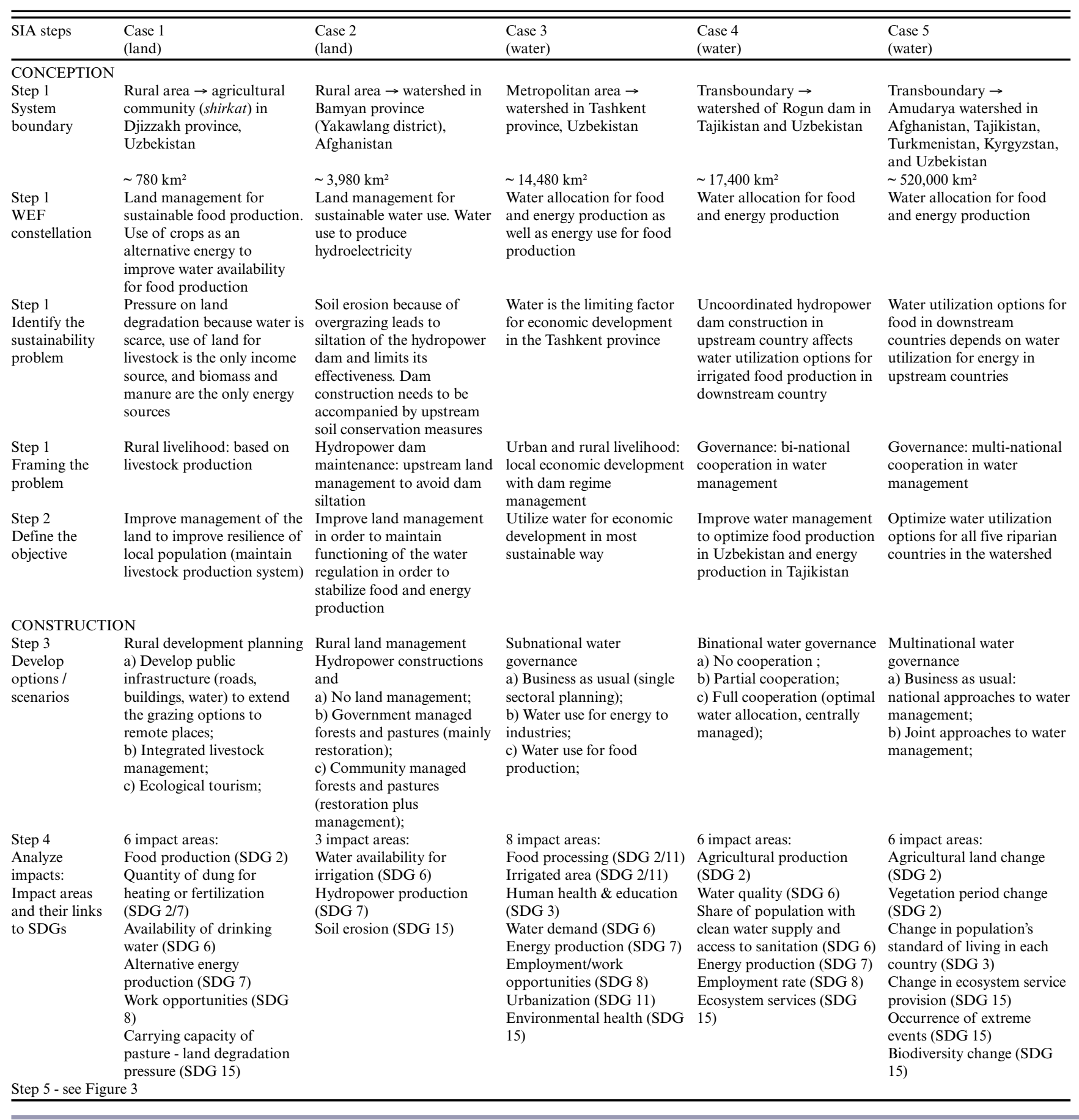

countries stopped supplying fossil fuels (e.g., coal and gas) to meet the energy demand of upstream countries during the winter period (Saidmamatov et al. 2020). In response to this complex situation, national water governance systems of the now independent Central Asian countries have been formulated, but they are unable to effectively mitigate the rapidly progressing environmental degradation of the Aral Sea basin.
The five case studies developed within this context ranged from pressure on land degradation in a water scarce rural area (780 $\mathrm{km}^{2}$ ) to multi-national transboundary water governance of the Amudarya watershed $\left(520,000 \mathrm{~km}^{2}\right.$; Fig. 2). The cases are characterized in Appendix 1 with key aspects on sustainability challenges and system boundaries and summarized in Table 2. 


\section{COMPARATIVE ANALYSIS OF THE SUSTAINABILITY IMPACT ASSESSMENT PROTOCOLS}

\section{Conception of WEF nexus cases in Central Asia}

Despite the considerable diversity across the five cases, water scarcity and the causal linkage between the three WEF dimensions was inherent to them all (Table 2). The spatial scale ranged from local (subnational) to multinational levels and spanned two orders of magnitude of spatial extent. From a societal perspective, all cases operate at the meso level, i.e., at the interface of larger worldview discourses and individual choices (Köhler et al. 2019). From the perspective of the WEF constellation, the five cases fall into two groups. The first group includes Cases 1 and 2, in which land management for water saving and water storage purposes was the key component of the WEF nexus. The system boundaries in these cases were smaller in size compared to the river basins of cases 3-5. With a total area of $780 \mathrm{~km}^{2}$ in Forish district in Uzbekistan, Case 1 assessed the potential impacts of developing energy production from livestock manure and increasing water availability for drinking purposes through groundwater recharge. Maintenance of soil quality and avoidance of land degradation are seen as main measures for ensuring water storage capacity in the ecosystem and respective water availability for the local population. This addressed the vulnerability of the social-ecological system (Folke 2006), in which avoidance of land degradation, e.g., soil erosion and overgrazing, associated with the increased number of livestock in pasture areas was emphasized. In this most local of the five cases, placed-based factors determining the local solution for the management of energy scarcity via the utilization of dung played the largest role. With the upstream land management scenarios to the functioning of hydropower plants, Case 2 addressed a mainly social-technological system (Geels 2004), in which the governance mechanism (government managed or community managed) had economic and environmental consequences, such as population relocation, sediment transport from upstream catchment area into the reservoir, soil erosion in upstream, soil salinity in downstream, and potential flooding. In this case however, the link to food production within the WEF nexus concept was least explicitly conceptualized.

Cases 3-5 make up the second group, in which water allocation for food and/or for energy production, and thereby for economic development and well-being, were the main WEF nexus constellations. Governance of the social-technological system was the approach to the WEF nexus problem framing in these cases. For instance, the Chirchik river basin in Tashkent province (Case 3) provides water for food and produces $54 \%$ of the total hydropower energy produced in Uzbekistan (Uzhydro 2019, unpublished manuscript). The area is considered to be suitable for irrigated food production because of its fertile soils, low rate of soil salinity, and availability of water. However, rapid population growth around the capital city of Tashkent requires transitions from mainly primary production in the agricultural sector to value chain related higher levels of economic development. The food aspect in the WEF nexus would thereby shift from a direct to an indirect level in that food security would be assured via water-based energy production for other economic sectors than irrigated agriculture.

At the transboundary levels (Cases 4 and 5), the focus was mostly on the Amudarya river basin, the largest river basin in Central
Asia ( $~ 520,000 \mathrm{~km}^{2}$ catchment area) that holds complex political character because of the competition between water for hydropower production (mainly in the upstream countries) and water for irrigated food production (especially in the downstream countries), which is a typical WEF nexus challenge. Pumping water resources for agriculture to produce food in downstream countries consumes energy, which exacerbates the complication further. Water governance at national and international levels were understood to be the main lever for sustainable WEF nexus management in these cases.

Whereas the conceptualization of the WEF nexus problem differed across the five cases, they all managed to address key sustainability issues that were appropriate to the respective case system boundaries. The WEF nexus is intertwined in irrigated agriculture systems, and sustainable development requires effective and coordinated management of the nexus (Murzakulova et al. 2020). In all five cases, through the lenses of WEF nexus, we tried to find solutions regarding trade-offs between agriculture, energy production, and environmental degradation, balancing interests between sectors and national interests, reflecting key WEF challenges in this region. However, irrigated agricultural production itself implies a WEF issue related to the economic and environmental implications of energy use in pumping water for agriculture (de Vito et al. 2017). Indeed, though pressurized irrigation systems (e.g., drip or sprinkler) offer substantial water saving potential, they are associated with high energy costs (Avellan et al. 2018), though there are considerable opportunities to save water with the predominant surface irrigated systems (Webber et al. 2006, 2008). Finally, WEF nexus is also a useful tool to assess the potential of agriculture to boost energy provision through the cultivation of bioenergy crops (Mouratiadou et al. 2020). That these elements did not appear in either the scenario design or evaluation steps of our cases may reflect both the different context of agriculture and irrigation in the region as well as a bias given the strong focus on competition between agriculture and energy sectors.

\section{Construction of WEF nexus cases in Central Asia}

The construction of the impact assessments was linked to decision options around scenario development, the choice of indicators and impact areas and their link to the SDGs, and the comparison of the scenario impacts. Four out of the five cases developed three scenarios; Case 5 developed only two scenarios (Table 2; Fig. 3). In each case study, the developed scenarios reflected the specific system boundaries determined by the spatial scales and decisionmaking levels at which the WEF nexus issues were addressed. For instance, at large-scale (bi-national and multi-national) levels in Central Asia, trade-offs and sustainability problems regarding unbalanced benefit and cost sharing between upstream and downstream countries are dominant. Transboundary water governance is the lever for developing solution options in these cases (e.g., Cases 4 and 5). At national and subnational watersheds in economically developing (metropolitan) regions, sustainability problems arise from trade-offs regarding water utilization for economic development, including the provision of employment opportunities, and adverse environmental and social impacts. Irrigated food production is only one of many possible water utilizations. In these cases, subnational water governance needs to consider both economic development and sustainability impacts to leverage sustainable solutions (Case 3). Finally, two cases were situated in national and subnational watersheds in 
Fig. 3. Results of participatory scenario assessments of the five cases. The number ranges mean: $0=$ no impact; -1 and $+1=$ moderate negative and positive impact, respectively; -2 and $+2=$ high negative and positive impact, respectively; and -3 and $+3=$ extremely high negative and positive impact, respectively.
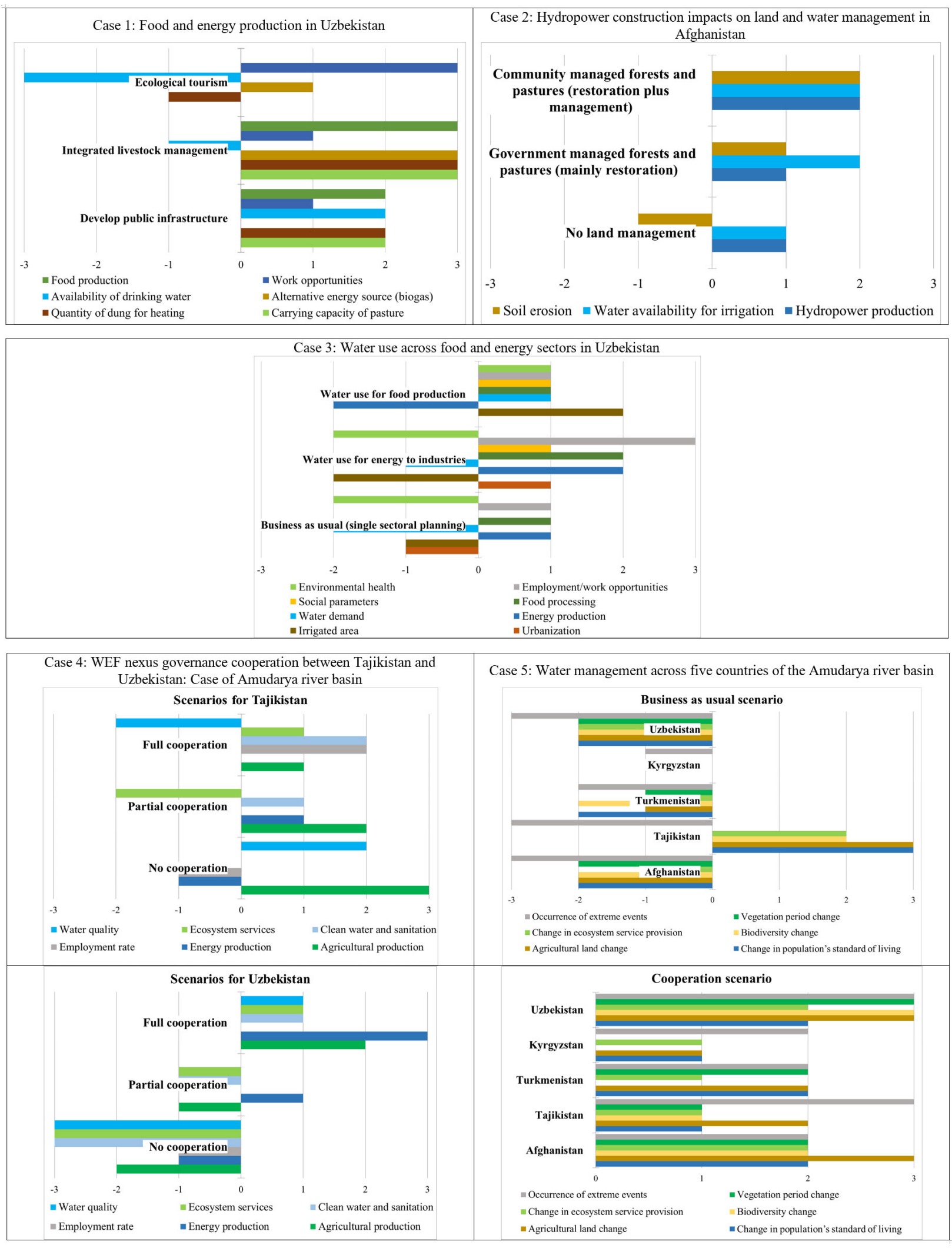
rural and agriculture dominated areas where natural conditions are vulnerable to land degradation such as erosion or salinization (Webber et al. 2009). Here the trade-off between water use for energy or agriculture is not direct and immediate but indirect and longer term. This is typical when land degradation and/or soil quality deterioration occurs as a consequence of hydropower construction and management and as a consequence of improper irrigation management. In the long term, land degradation and soil quality deterioration threaten irrigated food production. Rural land governance and conservation land management and farming practices are levers for developing solutions in these cases (Case 1 and 2). Here, decision making takes place at farming system level. Because of the study-like situation of the WEF case developments, the scenarios mainly focused on a variation of the direct drivers. External drivers such as climate change, population dynamics, and demand development were partly implicit in the large-scale case studies, but were not addressed in the small localscale case studies.

Regarding the impact areas, we associated them into SDGs. The results indicate that a comprehensive approach to all three sectors was implemented in three case studies (Cases 1, 3, and 4). Case 2 addressed the SDGs 6 and 7, but the food aspect is indirectly addressed through soil quality. Finally, the impact areas in Case 5 were linked more to food than water and energy, thereby not fully addressing the WEF system. Linking WEF nexus with a number of SDGs has received substantial attention in the literature. For instance, Boas et al. (2016) critically examined the SDGs, proposing that the connections between many of the goals are weak and rarely structural, without recognizing interconnections among different sectors. In contrast, for the case of South Asia, Rasul (2016) suggests that the SDGs are critically important for enabling food, water, and energy security in ways that do not undermine sustainability for future generations. In this study, the use of SDGs helped to understand the impact areas in the five study cases in relation to sustainable resource management.

The use of the SIA protocol for sustainability assessment facilitated the comparative case study analysis across scales. This is important for knowledge generalization (Magliocca et al. 2018) and knowledge synthesis so that local phenomena can enrich global assessments such as from the IPCC, ensuring their policy relevance (Minx et al. 2017).

\section{Cooperation of WEF nexus cases in Central Asia}

Participatory observation was used to better understand the group composition, dynamics, and communication styles as well as how the group involve and/or consider relevant actors and stakeholders. This allowed understanding the bias of the learning case in relation to real stakeholder situations. Observation is recognized as a method for collecting data about people, their behaviors, and local cultures (Wagner et al. 2012). Participant observation is a typical methodological approach, which Hatch (2002) defines as a data collection strategy where the researcher acts as a participant at some level in the settings he or she is studying. The cases tried to represent various levels of stakeholders' interests in their analyses that included perspectives from researchers, policy makers, international donor agencies, and local resource users. In order to come up with win-win situations, some groups even played the role of different country policy makers (e.g., one participant from Tajikistan in Case 4 took the role of a representative of Uzbek decision making to better understand concerns of the other countries and vice versa). Observations revealed that participants struggled with identifying relevant actors to represent during the impact assessment exercise. The SIA protocol proved to be insufficiently instructive for the design of the cooperation with actors and stakeholders in the WEF research. Indeed, our aim was not to show that the stakeholder involvement would work for implementing the WEF nexus, but instead that the process of an interdisciplinary approach, the workshop settings, and the SIA application helps experts work across disciplines to take a systems approach to WEF. Cooperation is a critical element across all impact assessment steps (Herrera and Kopainsky 2020), and it requires a sophisticated method to identify the relevant stakeholders in accordance with the context of the study, the problem statement, and the system boundaries (Reed et al. 2014) and vice versa (de Vente et al. 2016). The process of team selection and composition is crucial to insure adequate representation of disciplines and specific expert knowledge, gender, age, norms, and values (Bond et al. 2015). Here, SIA protocols need further development to include instructions for stakeholder co-operation, such as outlined in Morris et al. (2011). This is particularly important as methodological skills of transdisciplinary research have only recently begun to emerge in learning, teaching, and research (König 2015).

\section{CONTRIBUTION OF WEF NEXUS RESEARCH TO SUSTAINABLE DEVELOPMENT}

Being complex, uncertain, and dynamic in nature, this research resembles sustainability science. We applied the set of eight criteria for socially responsible and sustainable research processes (Daedlow et al. 2016) to evaluate systemic sustainability-related issues in WEF nexus research in a self-reflection approach.

Results revealed that four of the eight criteria were rated as highly or very highly relevant to the operationalization of the SIA protocol (Table 3 ). These include the approach to complexity and uncertainty, the integrative approach, the interdisciplinarity, and the reflection on impacts. These four criteria all address the multidimensionality inherent to sustainability problems (Köhler et al. 2019) as well as the uncertainty of the solution space, which allow for multiple solution pathways all requiring consideration in sustainability research (Rosenbloom 2017). With the scenariobased approach and the indicator-based multi-criteria analysis of the scenario assumptions, the SIA framework proved capable of dealing with complex, interdisciplinary, and impact-oriented characteristics of socially responsible research for sustainable development. This is a major advantage of the approach, which explains its increasing use in prominent studies of complex sustainability issues (Sheate et al. 2008, Stamford and Azapagic 2014). In the study situation, the participants implementing the SIA protocol were able to address these criteria.

The other four criteria, namely ethics, transdisciplinarity, transparency, and user orientation, were valued as less relevant for most of the case studies. These are the criteria that are most critical for respecting the social norms and values of actors involved in and/or affected by the outcomes of the impact assessment exercise. It is interesting to note that transparency criteria were considered least relevant for conducting the WEF 
Table 3. Self-reflection of the relevance of the eight criteria for socially responsible research processes to the five case studies.

\begin{tabular}{|c|c|c|c|c|c|}
\hline Criteria & $\begin{array}{l}\text { Case } 1 \\
\text { (land) }\end{array}$ & $\begin{array}{l}\text { Case } 2 \\
\text { (land) }\end{array}$ & $\begin{array}{l}\text { Case } 3 \\
\text { (water) }\end{array}$ & $\begin{array}{l}\text { Case } 4 \\
\text { (water) }\end{array}$ & $\begin{array}{l}\text { Case } 5 \\
\text { (water) }\end{array}$ \\
\hline Approach to complexity and uncertainty & ++ & +++ & +++ & ++ & +++ \\
\hline Ethics & ++ & +++ & - & ++ & - \\
\hline Integrative approach & +++ & ++ & +++ & +++ & +++ \\
\hline Interdisciplinarity & +++ & +++ & +++ & +++ & +++ \\
\hline Reflection on impacts & +++ & +++ & +++ & +++ & ++ \\
\hline Transdisciplinarity & +++ & + & +++ & ++ & + \\
\hline Transparency & + & - & - & + & - \\
\hline User orientation & + & +++ & ++ & + & +++ \\
\hline
\end{tabular}

- Not relevant, + relevant, ++ slightly relevant, +++ highly relevant

nexus impact assessment. Transparency requires clear, useroriented communication throughout all stages of the research process, which apparently was not the case in developing the research design by the groups. Transparency implies or suggests an adequate reflection of ethical issues (Daedlow et al. 2016), and thus the group representatives rated ethics relatively low. Ethical issues were not discussed at all during the impact assessment design process in Cases 3 and 5. Ethical requirements to sustainability research is particularly relevant for the approach to stakeholder involvement and cooperation (Lam et al. 2020). The comparably little relevance given to these normative aspects of research for sustainable development is well in line with the finding that the SIA protocol was unsuccessful in providing guidance for the design of the cooperation with actors and stakeholders in the WEF research. Previous research on sustainable development highlighted the importance of these normative issues, such as the clarity and transparency of procedures to achieve robust results (Adler and Hadorn 2014), as well as the capability for self-reflection under the premise of responsibility throughout the research process (Stahl 2013). This is clearly a challenge for future research.

\section{CONCLUSION}

The water-energy-food nexus concept was operationalized for five case studies in Central Asia during a one-week international summer school in a learning setting. The research question was to analyze if and to what extent the application of the SIA framework and protocol is a suitable tool for enabling systemic sustainability-oriented research. The relevance of this research lies in the need for scholarship about systemic methods that support working across disciplines.

By providing in-depth case study analysis of the five sustainability impact assessment steps in the selected study areas, the study also revealed the importance of systems' boundary definition in conducting impact assessment: spatial scales, governance levels, stakeholders, and different complexity of impact assessment. The SIA protocol is instructive for the conception and construction of WEF nexus research, irrespective of spatial scale or decisionmaking level. The latter determines how the WEF nexus has to be conceptualized (causal relations between utilization of water, energy and food) and how the assessment is constructed regarding scenario development and selection of sustainability issues (impact areas) addressed in the assessment. The SIA steps are generic enough to be applicable in all cases studied. The use of the protocol thereby facilitates comparative meta-analyses of case studies for synthesis and upscaling. This is seen as a particular asset because many studies addressing global challenges such as climate change or economic development suffer from inadequate local differentiation.

The SIA protocol is less instructive for the design of the cooperation with actors and stakeholders in the WEF research. Because cooperation is a critical element across all impact assessment steps, this is considered a severe drawback of the SIA protocol. It also constraints a justified selection and weighing of the sustainability issues addressed in the impact assessment.

Applying the SIA protocol for the design of the WEF nexus research helped workshop participants to understand the complexity of the problem and to establish the interdisciplinary cooperation. It was less instructive in designing the transdisciplinary cooperation particularly with regards to the distinction between actors making decisions in a sustainability context or actors subject to the (positive and negative) sustainability impacts.

There is limited reflection in the SIA literature on how assessment design (integration/choice of scenarios, indicators, and impact areas and their analysis) and results depend on group composition and the particular expertise, norms, and values of the participants from academic and non-academic backgrounds. This is seen as a critical area for future research.

Responses to this article can be read online at: https://www.ecologyandsociety.org/issues/responses. php/12891

\section{Author Contributions:}

Ahmad Hamidov: conceptualization, methodology, analysis, result interpretation, writing - original draft preparation, and addressing comments. Katrin Daedlow: conceptualization, methodology, analysis, result interpretation, writing: reviewing and editing, and addressing comments. Heidi Webber: conceptualization, methodology, result interpretation, writing: reviewing and editing, and addressing comments. Hussam Hussein: conceptualization, methodology, result interpretation, writing: reviewing and editing, and addressing comments. Ilhom Abdurahmanov: case study contribution, result interpretation. Aleksandr Dolidudko: case study contribution, result interpretation. Umida Solieva: case study contribution, result 
interpretation. Ali Yawar Seerat: case study contribution, result interpretation. Tesfaye Berhanu Woldeyohanes: case study contribution, result interpretation. Katharina Helming: conceptualization, methodology, analysis, result interpretation, writing: reviewing and editing, and addressing comments.

\begin{abstract}
Acknowledgments:
We would like to thank the participants of WEFCA (Sustainability Assessment of the Water-Energy-Food Nexus for Irrigated Agriculture: Interdisciplinary Approaches for Central Asia) International Summer School for their active engagement during the event and for developing case studies. The summer school was financially supported by the Volkswagen Foundation (Az.: 94 751). Additionally, Ahmad Hamidov's research for this paper benefited from the German Research Foundation (DFG) within the frame of WEFUz project (GZ: HA 8522/2-1). We appreciate the support from Kevin Urbasch (Leibniz Centre for Agricultural Landscape Research) and Zafar Gafurov (International Water Management Institute-Central Asia Office) in preparing the spatial map.
\end{abstract}

\section{Data Availability:}

The data that support the findings of this study can be requested from the corresponding author. Because of the privacy of summer school participants, the data are not publicly available.

\section{LITERATURE CITED}

Abdurahmanov, I. 2015. Analysis of pasture land degradation reasons in Farish district of Jizzakh region of Uzbekistan. Pages 185-192 in Proceedings of Theory Meets Practice in GIS. Debrecen University Press, Debrecen University Press, Debrecen, Hungary. [online] URL: https://giskonferencia.unideb.hu/arch/ GIS Konf kotet 2015.pdf?fbclid=IwAR3UiUUiFL8By1JBrsyc1BiSShfmm78VFv8nvrdugBCRuHfbHIEmQWQixo

Adler, C. E., and G. H. Hadorn. 2014. The IPCC and treatment of uncertainties: topics and sources of dissensus. Wiley Interdisciplinary Reviews: Climate Change 5(5):663-676. https:// doi.org/10.1002/wcc.297

Albrecht, T. R., A. Crootof, and C. A. Scott. 2018. The waterenergy-food nexus: a systematic review of methods for nexus assessment. Environmental Research Letters 13(4):043002. https://doi.org/10.1088/1748-9326/aaa9c6

Avellán, T., R. Ardakanian, S. R. Perret, R. Ragab, W. Vlotman, H. Zainal, S. Im, and H. A. Gany. 2018. Considering resources beyond water: irrigation and drainage management in the context of the water-energy-food nexus. Irrigation and Drainage 67 (1):12-21. https://doi.org/10.1002/ird.2154

Bäcklund, A. K. 2009. Impact assessment in the European Commission - a system with multiple objectives. Environmental Science \& Policy 12(8):1077-1087. https://doi.org/10.1016/j. envsci.2009.04.003

Bertelsen, O. W. 2000. Design artefacts: towards a design-oriented epistemology. Scandinavian Journal of Information Systems 12 (1):2. [online] URL: https://aisel.aisnet.org/sjis/vol12/iss1/2

Binder, C. R., G. Feola, and J. K. Steinberger. 2010. Considering the normative, systemic and procedural dimensions in indicator- based sustainability assessments in agriculture. Environmental Impact Assessment Review 30(2):71-81. https://doi.org/10.1016/ j.eiar.2009.06.002

Boas, I., F. Biermann, and N. Kanie. 2016. Cross-sectoral strategies in global sustainability governance: towards a nexus approach. International Environmental Agreements: Politics, Law and Economics 16(3):449-464. https://doi.org/10.1007/ s10784-016-9321-1

Bond, A., A. Morrison-Saunders, J. A. E. Gunn, J. Pope, and F. Retief. 2015. Managing uncertainty, ambiguity and ignorance in impact assessment by embedding evolutionary resilience, participatory modelling and adaptive management. Journal of Environmental Management 151:97-104. https://doi.org/10.1016/ j.jenvman.2014.12.030

Commission of the European Communities (CEC). 2009. Impact assessment guidelines. CEC, Brussels, Belgium.

Daedlow, K., A. Podhora, M. Winkelmann, J. Kopfmüller, R. Walz, and K. Helming. 2016. Socially responsible research processes for sustainability transformation: an integrated assessment framework. Current Opinion in Environmental Sustainability 23:1-11. https://doi.org/10.1016/j.cosust.2016.09.004

de Vente, J., M. S. Reed, L. C. Stringer, S. Valente, and J. Newig. 2016. How does the context and design of participatory decision making processes affect their outcomes? Evidence from sustainable land management in global drylands. Ecology and Society 21(2):24. https://dx.doi.org/10.5751/ES-08053-210224

de Vito, R., I. Portoghese, A. Pagano, U. Fratino, and M. Vurro. 2017. An index-based approach for the sustainability assessment of irrigation practice based on the water-energy-food nexus framework. Advances in Water Resources 110:423-436. https:// doi.org/10.1016/j.advwatres.2017.10.027

Djumaboev, K., O. Anarbekov, B. Holmatov, A. Hamidov, Z. Gafurov, M. Murzaeva, J. Sušnik, S. Maskey, H. Mehmood, and V. Smakhtin. 2020. Surface water resources. Pages 25-38 in S. Xenarios, D. Schmidt-Vogt, M. Qadir, B. Janusz-Pawletta, and I. Abdullaev, editors. The Aral Sea Basin: water for sustainable development in Central Asia. Routledge, New York, New York, USA. https://doi.org/10.4324/9780429436475-3

Djumaboev, K., T. Yuldashev, B. Holmatov, and Z. Gafurov. 2019. Assessing water use, energy use and carbon emissions in liftirrigated areas: a case study from Karshi Steppe in Uzbekistan. Irrigation and Drainage 68(3):409-419. https://doi.org/10.1002/ $\underline{\text { ird. } 2321}$

D’Odorico, P., J. Carr, C. Dalin, J. Dell'Angelo, M. Konar, F. Laio, L. Ridolfi, L. Rosa, S. Suweis, and S. Tamea. 2019. Global virtual water trade and the hydrological cycle: patterns, drivers, and socio-environmental impacts. Environmental Research Letters 14 (5):053001. https://doi.org/10.1088/1748-9326/ab05f4

Endo, A., M. Yamada, Y. Miyashita, R. Sugimoto, A. Ishii, J. Nishijima, M. Fujii, T. Kato, H. Hamamoto, M. Kimura, T. Kumazawa, and J. Qi. 2020. Dynamics of water-energy-food nexus methodology, methods, and tools. Current Opinion in Environmental Science \& Health 13:46-60. https://doi. org/10.1016/j.coesh.2019.10.004 
Esteves, A. M., D. Franks, and F. Vanclay. 2012. Social impact assessment: the state of the art. Impact Assessment and Project Appraisal 30(1):34-42. https://doi.org/10.1080/14615517.2012.660356

Fabiani, S., S. Vanino, R. Napoli, and P. Nino. 2020. Water energy food nexus approach for sustainability assessment at farm level: an experience from an intensive agricultural area in central Italy. Environmental Science \& Policy 104:1-12. https://doi. org/10.1016/j.envsci.2019.10.008

Folke, C. 2006. Resilience: the emergence of a perspective for social-ecological systems analyses. Global Environmental Change 16(3):253-267. https://doi.org/10.1016/j.gloenvcha.2006.04.002

Geels, F. W. 2004. From sectoral systems of innovation to sociotechnical systems: insights about dynamics and change from sociology and institutional theory. Research Policy 33 (6-7):897-920. https://doi.org/10.1016/j.respol.2004.01.015

Hamidov, A., and K. Helming. 2020. Sustainability considerations in water-energy-food nexus research in irrigated agriculture. Sustainability 12(15):6274. https://doi.org/10.3390/ $\underline{\text { su12156274 }}$

Hamidov, A., K. Helming, and D. Balla. 2016. Impact of agricultural land use in Central Asia: a review. Agronomy for Sustainable Development 36:6. https://doi.org/10.1007/s13593-015-0337-7

Hatch, J. A. 2002. Doing qualitative research in education settings. State University of New York Press, Albany, New York, USA.

Helming, K., K. Diehl, H. Bach, O. Dilly, B. König, T. Kuhlman, M. Pérez-Soba, S. Sieber, P. Tabbush, K. Tscherning, D. Wascher, and H. Wiggering. 2011. Ex ante impact assessment of policies affecting land use, Part A: analytical framework. Ecology and Society 16(1):27. [online] URL: https://dx.doi.org/10.5751/ ES-03839-160127

Helming, K., K. Diehl, D. Geneletti, and H. Wiggering. 2013. Mainstreaming ecosystem services in European policy impact assessment. Environmental Impact Assessment Review 40:82-87. https://doi.org/10.1016/j.eiar.2013.01.004

Herrera, H., and B. Kopainsky. 2020. Using system dynamics to support a participatory assessment of resilience. Environment Systems and Decisions 40:342-355. https://doi.org/10.1007/ s10669-020-09760-5

Hoff, H. 2011. Understanding the nexus. Background paper for the Bonn2011 Conference: The Water, Energy and Food Security Nexus. Stockholm Environment Institute, Stockholm, Sweden. [online] URL: https://www.sei.org/publications/understandingthe-nexus/

Howard, K. W. F., and K. K. Howard. 2016. The new "Silk Road Economic Belt" as a threat to the sustainable management of Central Asia's transboundary water resources. Environmental Earth Sciences 75(11):976. https://doi.org/10.1007/s12665-016-5752-9

Jalilov, S. M., S. A. Amer, and F. A. Ward. 2018. Managing the water-energy-food nexus: opportunities in Central Asia. Journal of Hydrology 557:407-425. https://doi.org/10.1016/j.jhydrol.2017.12.040

Jalilov, S. M., M. Keskinen, O. Varis, S. Amer, and F. A. Ward. 2016. Managing the water-energy-food nexus: gains and losses from new water development in Amu Darya River Basin. Journal of Hydrology 539:648-661. https://doi.org/10.1016/j.jhydrol.2016.05.071

Jones, D., and S. Gregor. 2007. The anatomy of a design theory. Journal of the Association for Information Systems 8(5):312-335. https://doi.org/10.17705/1jais.00129

Kasymov, U., and A. Hamidov. 2017. Comparative analysis of nature-related transactions and governance structures in pasture use and irrigation water in Central Asia. Sustainability 9(9):1633. https://doi.org/10.3390/su9091633

Keulertz, M., and E. Woertz. 2015. Financial challenges of the nexus: pathways for investment in water, energy and agriculture in the Arab world. International Journal of Water Resources Development 31(3):312-325. https://doi.org/10.1080/07900627.2$\underline{015.1019043}$

Kling, C. L., R. W. Arritt, G. Calhoun, and D. A. Keiser. 2017. Integrated assessment models of the food, energy, and water nexus: a review and an outline of research needs. Annual Review of Resource Economics 9:143-163. https://doi.org/10.1146/ annurev-resource-100516-033533

Köhler, J., F. W. Geels, F. Kern, J. Markard, E. Onsongo, A. Wieczorek, F. Alkemade, F. Avelino, A. Bergek, F. Boons, L. Fünfschilling, D. Hess, G. Holtz, S. Hyysalo, K. Jenkins, P. Kivimaa, M. Martiskainen, A. McMeekin, M. S. Mühlemeier, B. Nykvist, B. Pel, R. Raven, H. Rohracher, B. Sandén, J. Schot, B. Sovacool, B. Turnheim, D. Welch, and P. Wells. 2019. An agenda for sustainability transitions research: state of the art and future directions. Environmental Innovation and Societal Transitions 31:1-32. https://doi.org/10.1016/j.eist.2019.01.004

König, A. 2015. Changing requisites to universities in the $21 \mathrm{st}$ century: organizing for transformative sustainability science for systemic change. Current Opinion in Environmental Sustainability 16:105-111. https://doi.org/10.1016/j.cosust.2015.08.011

König, H. J., M. Sghaier, J. Schuler, M. Abdeladhim, K. Helming, J.-P. Tonneau, N. Ounalli, J. Imbernon, J. Morris, and H. Wiggering. 2012. Participatory impact assessment of soil and water conservation scenarios in Oum Zessar watershed, Tunisia. Environmental Management 50(1):153-165. https://doi.org/10.1007/ $\underline{\mathrm{s} 00267-012-9865-\mathrm{y}}$

König, H. J., S. Uthes, J. Schuler, L. Zhen, S. Purushothaman, U. Suarma, M. Sghaier, S. Makokha, K. Helming, S. Sieber, L. Chen, F. Brouwer, J. Morris, and H. Wiggering. 2013. Regional impact assessment of land use scenarios in developing countries using the FoPIA approach: findings from five case studies. Journal of Environmental Management 127:S56-S64. https://doi.org/10.1016/ j.jenvman.2012.10.021

Lam, D. P., E. Hinz, D. J. Lang, M. Tengö, H. von Wehrden, and B. Martín-López. 2020. Indigenous and local knowledge in sustainability transformations research: a literature review. Ecology and Society 25(1):3. https://doi.org/10.5751/ES-11305-250103

Löw, F., A. V. Prishchepov, F. Waldner, O. Dubovyk, A. Akramkhanov, C. Biradar, and J. P. A. Lamers. 2018. Mapping cropland abandonment in the Aral Sea Basin with MODIS time series. Remote Sensing 10(2):159. https://doi.org/10.3390/ $\underline{\text { rs10020159 }}$ 
Mackenzie, S. G., and A. R. Davies. 2019. SHARE IT: codesigning a sustainability impact assessment framework for urban food sharing initiatives. Environmental Impact Assessment Review 79:106300. https://doi.org/10.1016/j.eiar.2019.106300

Magliocca, N. R., E. C. Ellis, G. R. H. Allington, A. de Bremond, J. Dell'Angelo, O. Mertz, P. Messerli, P. Meyfroidt, R. Seppelt, and P. H. Verburg. 2018. Closing global knowledge gaps: producing generalized knowledge from case studies of socialecological systems. Global Environmental Change 50:1-14. https://doi.org/10.1016/j.gloenvcha.2018.03.003

Menga, F., and N. Mirumachi. 2016. Fostering Tajik hydraulic development: examining the role of soft power in the case of the Rogun Dam. Water Alternatives 9(2):373-388. [online] URL: https://www.water-alternatives.org/index.php/alldoc/articles/vol9/ v9issue2/321-a9-2-11/file

Miah, S. J., D. Kerr, and L. von Hellens. 2014. A collective artefact design of decision support systems: design science research perspective. Information Technology \& People 27(3):259-279.

Micklin, P. 2016. The future Aral Sea: hope and despair. Environmental Earth Sciences 75(9):844. https://doi.org/10.1007/ $\underline{\text { s12665-016-5614-5 }}$

Minx, J. C., M. Callaghan, W. F. Lamb, J. Garard, and O. Edenhofer. 2017. Learning about climate change solutions in the IPCC and beyond. Environmental Science \& Policy 77:252-259. https://doi.org/10.1016/j.envsci.2017.05.014

Morgan, R. K. 2012. Environmental impact assessment: the state of the art. Impact Assessment and Project Appraisal 30(1):5-14. https://doi.org/10.1080/14615517.2012.661557

Morris, J. B., V. Tassone, R. De Groot, M. Camilleri, and S. Moncada. 2011. A framework for participatory impact assessment: involving stakeholders in European policy making, a case study of land use change in Malta. Ecology and Society 16 (1). https://doi.org/10.5751/ES-03857-160112

Mouratiadou, I., T. Stella, T. Gaiser, B. Wicke, C. Nendel, F. Ewert, and F. van der Hilst. 2020. Sustainable intensification of crop residue exploitation for bioenergy: opportunities and challenges. GCB Bioenergy 12:71-89. https://doi.org/10.1111/ gcbb.12649

Murzakulova, A., D. Schmidt-Vogt, D. Balla, D. Darr, A. Hamidov, U. Kasymov, R. Mendelevitch, and S. Orazgaliyev. 2020. Water for agriculture and other economic sectors. Pages 86-99 in S. Xenarios, D. Schmidt-Vogt, M. Qadir, B. JanuszPawletta, and I. Abdullaev, editors. The Aral Sea Basin: water for sustainable development in Central Asia. Routledge, New York, New York, USA. https://doi.org/10.4324/9780429436475-7

Pintér, L., P. Hardi, A. Martinuzzi, and J. Hall. 2012. Bellagio STAMP: principles for sustainability assessment and measurement. Ecological Indicators 17:20-28. https://doi. org/10.1016/j.ecolind.2011.07.001

Qi, J., S. Pueppke, R. Kulmatov, T. Bobushev, S. Tao, T. I. Yespolov, M. Beksultanov, and X. Chen. 2020. The complexity and challenges of Central Asia's water-energy-food systems. Pages 71-85 in G. Gutman, J. Chen, G. M. Henebry, and M. Kappas, editors. Landscape dynamics of drylands across Greater
Central Asia: people, societies and ecosystems. Springer Nature, Cham, Switzerland.

Rasul, G. 2016. Managing the food, water, and energy nexus for achieving the sustainable development goals in South Asia. Environmental Development 18:14-25. https://doi.org/10.1016/j. envdev.2015.12.001

Reed, M. S., L. C. Stringer, I. Fazey, A. C. Evely, and J. H. J. Kruijsen. 2014. Five principles for the practice of knowledge exchange in environmental management. Journal of Environmental Management 146:337-345. https://doi.org/10.1016/j.jenvman.2014.07.021

Reidsma, P., S. Janssen, J. Jansen, and M. K. van Ittersum. 2018. On the development and use of farm models for policy impact assessment in the European Union-A review. Agricultural Systems 159:111-125. https://doi.org/10.1016/j.agsy.2017.10.012

Rosenbloom, D. 2017. Pathways: an emerging concept for the theory and governance of low-carbon transitions. Global Environmental Change 43:37-50. https://doi.org/10.1016/j. gloenvcha.2016.12.011

Saidmamatov, O., I. Rudenko, S. Pfister, and J. Koziel. 2020. Water-energy-food nexus framework for promoting regional integration in Central Asia. Water 12(7):1896. https://doi. org/10.3390/w12071896

Sheate, W. R., M. R. do Partidário, H. Byron, O. Bina, and S. Dagg. 2008. Sustainability assessment of future scenarios: methodology and application to mountain areas of Europe. Environmental Management 41(2):282-299. https://doi.org/10.1007/ $\underline{\mathrm{s} 00267-007-9051-9}$

Soroush, M. 2018. Ancient irrigation systems of the Aral Sea area: the history, origin, and development of irrigated agriculture. Central Asian Survey 37(3):493-496. https://doi. org/10.1080/02634937.2018.1445595

Stahl, B. C. 2013. Responsible research and innovation: the role of privacy in an emerging framework. Science and Public Policy 40(6):708-716. https://doi.org/10.1093/scipol/sct067

Stamford, L., and A. Azapagic. 2014. Life cycle sustainability assessment of UK electricity scenarios to 2070. Energy for Sustainable Development 23:194-211. https://doi.org/10.1016/j. esd.2014.09.008

Wagner, C., B. Kawulich, and M. Garner. 2012. Doing social research: a global context. McGraw-Hill, New York, New York, USA.

Webber, H., C. A. Madramootoo, M. Bourgault, M. G. Horst, G. Stulina, and D. L. Smith. 2006. Water use efficiency of common bean and green gram grown using alternate furrow and deficit irrigation. Agricultural Water Management 86(3):259-268. https://doi.org/10.1016/j.agwat.2006.05.012

Webber, H., C. A. Madramootoo, M. Bourgault, M. G. Horst, G. Stulina, and D. L. Smith. 2008. Plant and soil water dynamics of alternate furrow and regulated deficit irrigation for two legume crops. Transactions of the American Society of Agricultural and Biological Engineers 51(4):1341-1350.

Webber, H., C. Madramootoo, M. Bourgault, M. Horst, G. Stulina, and D. Smith. 2009. Response of two legume crops to 
soil salinity in gypsiferous soils. Irrigation and Drainage 58 (5):586-595. https://doi.org/10.1002/ird.448

Weitz, N., C. Strambo, E. Kemp-Benedict, and M. Nilsson. 2017. Closing the governance gaps in the water-energy-food nexus: insights from integrative governance. Global Environmental Change 45:165-173. https://doi.org/10.1016/j.gloenvcha.2017.06.006

Yu, Y., Y. Pi, X. Yu, Z. Ta, L. Sun, M. Disse, F. Zeng, Y. Li, X. Chen, and R. Yu. 2019. Climate change, water resources and sustainable development in the arid and semi-arid lands of Central Asia in the past 30 years. Journal of Arid Land 11(1):1-14. https://doi.org/10.1007/s40333-018-0073-3 


\section{Appendix: Description of five exemplary WEF nexus cases}

Case 1: Food and energy production in an integrated livestock system in Forish district, Uzbekistan System boundaries, WEF problem and objective definition: Forish is a district in Djizzakh province of Uzbekistan with about $780 \mathrm{~km}^{2}$ area, where livestock is a main source of income though prolonged overgrazing has resulted in land degradation. In addition, a lack of fossil energy sources has driven local villagers to start using natural resources (e.g. firewood, shrubs, manure) for cooking and heating purposes. Combined, these two elements have further aggravated land degradation as manure is no longer available to improve soil fertility due to the decline in livestock and shrubs are no longer available for shading and grazing. Land degradation has deteriorated water storage capacity of the soils which in turn result in erosion and desertification (Abdurahmanov 2015). The main objective of this case study was to reverse land degradation and improve water storage and availability through alternative energy utilization.

Scenarios: Three scenarios for alternative resource management were considered: (1) develop public infrastructure to gain access to remote grazing areas, (2) use integrated livestock management to improve grazing conditions and livestock quality (including, potential bioenergy production), and (3) promote ecological tourism to develop alternative income sources and reduce pressure on land resources.

Impact areas: Six indicators were considered for the impact assessment: (a) pasture carrying capacity; (b) quantity of dung for heating; (c) alternative energy production options; (d) availability of drinking water; (e) work opportunities; (f) food production. Through the six indicators the group addressed WEF relevant SDGs 2, 6 and 7. Additionally, impact areas related to decent work and economic development (SDG 8) as well as pasture management (SDG 15) were addressed.

Results: The findings reveal that the integrated livestock management scenario was the best option with regards to most indicators (Table 2). However, the scenario provided fewer job opportunities and the availability of drinking water was reduced. The ecological tourism scenario only scored well for the provision of job opportunities. The scenario of improving public infrastructure was ranked between the two. Although each scenario contributed to improving the quality of life, integrated livestock management increased energy sources, employment options, industrialization, food availability and pasture restoration, and also mitigated grazing land degradation. If no intervention is done in the district, the grazing land is expected to further degrade and may cause ecological and social deterioration.

Case 2: Hydropower construction impacts on land and water management in Yakawalang district, Afghanistan

System boundaries, WEF problem and objective definition: Yakawalang is mountainous and one of the largest district of Bamyan province in Afghanistan with an area of approximately $3,980 \mathrm{~km}^{2}$. The main source of income in this district is livestock production and irrigated agriculture. Water shortage, soil salinity, low crop productivity, lack of access to sustainable electricity and soil erosion are significant challenges. The government of Afghanistan has recently suggested to construct a hydropower plant with a dam reservoir on the Band-e-Amir River in the district to provide electricity, which may have implications for water availability for irrigation in terms of quantity, quality, reliability and timing of water delivery constituting a typical WEF nexus constellation. As the mountainous area is very vulnerable to soil erosion, the dam can be expected to quickly suffer from siltation and loose its capacity if construction was not accompanied by soil conservation management practices. The objective of this study was to conduct an exante SIA of alternative land management scenarios in order to maintain functioning of the water regulation for stabilizing food and energy production in the study area. 
Scenarios: The study tested three scenarios that included hydropower construction with: (1) no land management, (2) government managed forests and pastures (mainly restoration), and (3) community managed forests and pastures (restoration plus management).

Impact areas: Three impact areas were selected, focusing on water availability for irrigation (SDG 6), hydropower production (SDG 7) and soil erosion (SDG 15). Food production was indirectly addressed via the soil erosion indicator. Soil erosion prevention measures such as afforestation would reduce available area for food production but could increase soil quality and therefore productivity on the remaining land, particularly at long term.

Results: The results indicated that in scenario 1 (no land management governance), dam development would not take into account soil erosion issue and reservoir would steadily accumulate the sediments transported from upstream. This would reduce the effective capacity of the reservoir, which may lead to either reduced hydropower generation or higher operation costs in the long term. Scenario 2 (government managed land) provided better benefits in the short to medium term due to reduced soil erosion, and with less sediment accumulation in the reservoir. Nevertheless, unclear ownership rights issues over newly forested areas would be expected to lead to classic common-pool resource dilemma in which would lead to either a gradual decline in the forest density with time or impose additional operation expenses in terms of forest protection services. Under scenario 3 (community managed land), the sustainability of forested areas was expected to be secured through endowment of the local communities with ownership rights. This scenario offered better prospects for hydropower generation and irrigation supply regulation due to relatively greater reductions in soil erosion and prevention of sediment accumulation in the reservoir. The total net benefits of this scenario were estimated to be larger than the two scenarios, with it addressing the needs of both downstream and upstream communities.

Case 3: Water use across food and energy sectors in Tashkent Province, Uzbekistan

System boundaries, WEF problem and objective definition: Located in the northeastern part of Uzbekistan, Tashkent province receives water for irrigation purposes from the Tien Shan Mountains through Chirchik River and has an area of about $14,480 \mathrm{~km}^{2}$. This river has 19 hydropower plants which produce about $54 \%$ of the total hydropower energy in Uzbekistan. Water is the limiting factor for economic development in Tashkent province, which hosts about $9 \%$ of the 33.8 million inhabitants of Uzbekistan. Considering current energy demand, the future industrialization potential even drastically increasing energy demand, and the important role of the province in providing food security for Uzbekistan, the aim of the study was to carry out a SIA of alternative water utilization scenarios for economic development of the region.

Scenarios: Three scenarios were developed: (1) business as usual, meaning lack of timely irrigation water delivery to farmers and poor environmental quality in the region, (2) water use for food production to allow intensification of agriculture, and (3) water use for energy production to strengthen industrial processing.

Impact areas: Eight impact areas were identified addressing WEF sectors: food production and processing and total irrigated area (SDG 2); water demand (SDG 6); energy production (SDG 7); human health and education (SDG 3); employment and work opportunities (SDG 8); sustainable urbanization (SDG 11); and environmental health (SDG 15).

Results: Scenario analysis results indicated that the industrial processing and the agricultural intensification scenarios were better options for the province. Although it was difficult to prioritize the use of water for energy in the industrial processing scenario or to use for food production with the agricultural intensification, 
the study concluded that the current business as usual scenario was least suitable for sustainable development.

Case 4: WEF nexus governance cooperation between Tajikistan and Uzbekistan: Case of Amudarya river basin

System boundaries, WEF problem and objective definition: This case study dealt with the collaboration between upstream Tajikistan and downstream Uzbekistan in the governance of the WEF nexus of the Rogun dam area (ca. 17,400 $\mathrm{km}^{2}$ ), a sub-basin of the Amudarya river. Uncoordinated construction of the Rogun dam for hydropower purposes, originally started in 1982 in Tajikistan (Menga and Mirumachi 2016), affects water utilization options for irrigated food production in Uzbekistan. This aim of the SIA was to explore the governance of WEF nexus in the Amudarya river basin to seek regional solutions to common challenges.

Scenarios: Three scenarios, representing different degrees of cooperation between upstream country Tajikistan and downstream country Uzbekistan in the WEF nexus governance, were developed: (1) full cooperation, (2) partial cooperation, (3) no cooperation.

Impact areas: The study covered all three WEF-related SDGs of agricultural production (SDG 2), irrigation water quality as well as clean water supply and sanitation (SDG 6); energy production (SDG 7); as well as employment rate (SDG 8); and the provision of ecosystem services (SDG 15).

Results: Results showed that both countries would benefit from mitigating tradeoffs and maximizing synergies when they fully cooperate. Under full cooperation, the downstream country Uzbekistan would be better off in all indicators while the upstream country Tajikistan would face trade-offs regarding water quality, energy and agricultural production. It would however also gain in terms of environmental and social aspects. Overall, Tajikistan would not be affected much by the degree of collaboration, whereas Uzbekistan highly depends on the degree of cooperation.

Case 5: Water management across five countries of the Amudarya river basin System boundaries, WEF problem and objective definition: The Amudarya basin is the largest river basin in Central Asia with an area of 520,000 $\mathrm{km}^{2}$ (Djumaboev et al. 2020). The basin is characterized by a complex political situation due to the transnational competition between water for agriculture and water for hydropower. Moreover, using lift irrigation to produce food and cultivate cotton in downstream countries is highly energy consuming and exacerbates the challenges. The case developed and analyzed transboundary governance scenarios for shared water management in the Amudarya river basin, explicitly considering future climate change.

Scenario: Two scenarios were assessed: (1) business-as-usual and (2) transboundary cooperative water management between five countries Afghanistan, Tajikistan, Turkmenistan, Kyrgyzstan, and Uzbekistan.

Impact areas: Out of the three WEF-related SDGs only food production (SDG 2) was explicitly addressed with the indicators agricultural land change and vegetation period change. In addition, living standards (SDG 3 ) in affected countries and the quality of the terrestrial ecosystem (SDG 15) were addressed, the latter via three indicators: ecosystem service provision, occurrence of extreme events, and biodiversity.

Results: The assessment found that the benefits gained from cooperative, transboundary governance surpassed the benefits acquired from individual, national level governance. In particular, the management of extreme events, which are expected to become more frequent because of climate change, was found to be more effective with transboundary cooperation. Benefit sharing mechanisms during transboundary water 
resource management could result in new profitable options for economic development. The results can be used for the demonstration of importance in regional cooperation. 